Journal of Science, 66, 13; 1970). Very few scientists seem to make the attempt to keep in touch with current literature; only 20 per cent consult the register of current research in South Africa while even fewer, less than 15 per cent, consult sources of information about foreign research. This perhaps explains the large amount of duplication in South African research. Almost a fifth of those who reported that their work turned out to be a duplication of research elsewhere had failed to conduct an adequate literature survey first, while another tenth claimed that the original papers had been published in a foreign language. In more than 30 per cent of the incidents, publication of the papers had occurred within a few months of one another.

The South African scientists also seem to have a poor access to the results of work published in a foreign language. About 60 per cent of scientists can read papers in German, 25 per cent in French and only 2 per cent in Russian. Since the scientists are not at all well served by translation services this puts them at a considerable disadvantage internationally.

The financial rewards for scientists in South Africa do little to compensate for their isolation. Another survey published in the South African Journal of Science $(65,329$; 1969) shows that in 1967 the small group of three thousand (white) research scientists in South Africa earned an average of R4,000 a year,

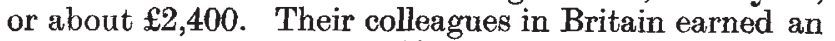
average of $£ 2,300$ (Nature, 226, 398; 1970). The British scientists have to pay higher taxes, but the cost of living in the two countries is much the same. In South Africa, university and industrial scientists are the best paid with an average salary of $R 4,600$ while scientists in organizations such as the large Council for Scientific and Industrial Research and the Atomic Energy Board earn about R4,000 and government scientists lag behind with R3,400 a year. Medical research workers, with an average salary of $\mathrm{R} 6,200$, earn substantially more than other scientists. Engineers are the next best paid, with mathematicians and chemists closely behind, and physicists and biologists are the most poorly paid.

All the scientists included in the survey have university degrees and in most fields of research they are divided fairly evenly into three groups: those with doctorates, those with a master's degree, and those with first degrees. Seventy-five per cent of the scientists obtained their highest qualifications at a South African university. British or Commonwealth universities account for a further 11 per cent, 8.5 per cent qualified on the continent and $4 \cdot 3$ per cent in the United States. With only about 10 per cent of their students going on to an honours degree course after a general degree the South African universities apparently find it hard to recruit enough staff to maintain their scientific research and teaching programmes.

\section{BLOOD GROUPS British Tribal Groups}

The British people are a long way from sharing a common ancestry. Not only is there a striking genetic difference between the English on the one hand, and the Scots, the Welsh and the Irish on the other, but there are also marked regional variations within the national borders themselves. This conclusion has emerged from a study of the distribution of blood groups in the UK, carried out by Dr Ada Kopec at the Serological Population Genetics Laboratory at St Bartholomew's Hospital (The Distribution of the Blood Groups in the $U K$, Oxford University Press, £8.50). The study, which was started in 1952, is based on blood donors' record cards, and has involved a sample size of more than half a million people.

The most striking difference is that between the distribution of blood groups in the Celtic countries, compared with Anglo-Saxon England. It seoms that the blood spilt in the battles between the Picts and Scots and the Roman armies was predominantly group $O$, because that is still the most common blood group in Scotland, Wales and Northern. Ireland. In England, on the other hand, group $\mathrm{A}$ is in some regions more common than group $\mathrm{O}$, and it is significantly more common there than it is in the countries which boast Celtic ancestry. The other broad variation, which probably owes its existence to the ethnic backgrounds of Celt and Anglo-Saxon, is the difference in the distribution of groups B and AB. These groups occur more frequently in Wales, Scotland and Northern Ireland than they do in England.

The most interesting variations are those within national borders. In the extreme north-east of Scotland, for example, there is a marked increase in the frequency of $\mathrm{AB}$ and $\mathrm{B}$ phenotypes, and a correspond. ing decrease in group A. On the other hand, in the region around the Wash, the most common blood group is $A$, and there is a corresponding decrease in $O$ phenotypes. These variations are marked, and there seems to be an abrupt change in the distribution at the borders of the region enclosing these populations. Such marked and abrupt changes are difficult to explain by ethnic background, unless it is assumed that populations in these areas are much less geographically mobile than populations in the rest of the UK, and that they represent patches of population which derive from an ethnic background that has been relatively undiluted by immigration from other parts of the UK.

As far as immigration from outside the United Kingdom is concerned, this seems to have increased the incidence of $A B$ and $B$ phenotypes. Such changes are most marked in London and Birmingham, but there is also evidence that the frequency of $\mathrm{AB}$ and $\mathrm{B}$ phenotypes is increasing in most parts of England, both from immigration from outside the UK as well as from Scotland, Wales and Ireland. Dr Kopeć could, however, find few significant differences in the distribution of rhesus negatives in the UK, and if there are differences, they must be small.

\section{TELESCOPES \\ Delays with Giant Blank}

THE slow gestation of the six-metre mirror for the Zelenchukskaya Observatory in the Caucasus is apparently causing some comment in Soviet technical circles. Pravda, it would appear, has been receiving queries from its readers as to the exact stage of progress of the mirror, and has accordingly sent a special correspondent to the unnamed factory where the mirror is under construction.

From his account it would seem that the 40-tonne blank, which is described as being made of a "special, non-crystallizing glass", has now passed through its 